\title{
Puzzling global stochastic trends in growth, interest and inflation and the Volcker disinflation
}

\author{
Reinhold Heinlein*1 and Hans-Martin Krolzig² \\ ${ }^{1}$ Keele Management School, Keele University, Darwin Building, Staffordshire ST5 5BG \\ ${ }^{2}$ School of Economics, University of Kent, Keynes College, Canterbury CT2 7NP
}

May 2016

\begin{abstract}
This paper aims to identify the stable long-run relationships as well as unstable driving forces of the world economy using an aggregated approach involving the four largest currency blocks. The small global cointegrated VAR model encompasses aggregated quarterly US, UK, Japanese and Euro Area data for the post-Bretton-Woods era. Three stable longrun relationships are found: output growth, the term spread and a measure of the inflation climate. The common stochastic trend of the global macro economy is dominated by the cumulated real short-term interest rate shocks, reflecting the strong increase of the global real rates during the Volcker disinflation period as a dominating event of the last 40 years of macro history.
\end{abstract}

Keywords: Cointegration; Real interest rates; Volcker disinflation; Multi-country model; Divisia index.

JEL classification: C32; C50; C82.

\section{Introduction}

Certain historical episodes left a long lasting impact on the world economy. Under the presence of unit roots, macroeconomic shocks might not only have a temporary impact at the time they

\footnotetext{
${ }^{*}$ Corresponding author, email: r.heinlein@ @eele.ac.uk (R. Heinlein). We are grateful to Miguel Leon-Ledesma, Helmut Lütkepohl and the seminar audiences at Keele University, DIW Macroeconometric Workshop 2012, Berlin, and SNDE 2014, New York. The usual disclaimer applies.
} 
occur but can cause permanent changes. An epoch which exerted a long lasting influence on the history of the world economy was surely the rigorous monetary policy regime of the Fed chairman Paul Volcker from 1979 to 1982, referred to by Goodfriend and King (2005) as the 'incredible' Volcker Disinflation. The results were not only the transition of the world economy of the epoch of the 'Great Inflation' to the period of the 'Great Moderation'. It also led to a dramatic increase of the world real interest rate, which reversed only gradually over several decades. In their paper 'Perspectives on High World Real Interest Rates', Blanchard et al. (1984) assign the level shift of real rates at the end of the 1970s and beginning of the 1980s to a mixture of expansive fiscal and tight monetary policy.

In this paper we reconsider the issue by deriving the global common stochastic trends in the rates of growth, interest and inflation in an aggregated model of the world's four largest currency blocks. Our analysis is based on the cointegrated vector autoregressive (CVAR) approach of Johansen (1995) and Juselius (2006), which allows to structure the information embedded in the data along pulling and pushing forces. The pulling forces are the stable long-run cointegration relations reverting the economy back to the steady state after an unanticipated shock. The pushing forces are the common stochastic trends driving the evolving macroeconomy. The concept of a common stochastic trend is closely related to that of a global factor in dynamic factor models (see Forni et al., 2000), which allows for higher-dimensional systems but are limited by their dependence on the presumption of stationarity. Their derivation is essential for the understanding of economic systems and the formulation of macroeconomic theories. Our implementation of the CVAR approach relies on (i) aggregating a large data set to a global scale and (ii) using the Granger representation of the CVAR to derive the common stochastic trends.

We will find that the stochastic trend is dominated by accumulated shocks to the real shortterm interest rate. The nonstationary of the real interest rate and its central importance as the driving trend of the global macroeconomy is puzzling. It contradicts one of the key pillars of macroeconomic thought, the stylised fact of Kaldor (1957) that the rate of return on capital should be stable over a long time period. We will argue that this finding can be traced back to the immense level shift in the real rate during the Volcker disinflation and its gradual reversion over the last three decades. The presence of a unit root in the real interest rate has been discussed in a strand of literature starting with Rose (1988): "Is the Real Interest Rate Stable?". Rose found for several countries, data frequencies and samples a unit root in the nominal interest rate, but none in inflation, while assuming inflation-forecasting errors to be stationary, he claimed real rates are mostly nonstationary. Garcia and Perron (1996) attributed the non-stability of the real rate to level shifts, which they detected by using a Markov switching model. For US quarterly data from 1961 to 1986 they found a shift in 1973 and in 1981. With an improved set of unit root tests Rapach and Weber (2004) mostly confirmed the results of Rose (1988), with the difference that in many countries they found a unit root in inflation as well, but in most cases no evidence of cointegration to make the real rate stationary. With Bai and Perron (1998) tests for multiple structural breaks for 13 countries, Rapach and Wohar (2005) found similar breaks 
in inflation, nominal and real interest rates. Mostly the size of the breaks in nominal rates are found to be smaller than the breaks in inflation, hence resulting in structural breaks in real rates. They claimed the results are highly suggestive that the persistent changes in real rates are attributable to changes in monetary regimes.

The structure of the paper is as follows. In $\S 2$ we introduce the data set. The CVAR model is presented in $\S 3$. In $\S 4$ we identify the common stochastic trend and analyse its relation to the Volcker disinflation. The robustness of our results with regard to alternative aggregation methods is discussed in $\S 5$. Finally $\S 6$ concludes.

\section{The data}

In the following, we analyse the dynamics of a global macro model of inflation, output growth, and short- and long-term interest rates, $\boldsymbol{y}_{t}=\left(\pi_{t}, \Delta y_{t}, i_{t}, r_{t}\right)^{\prime}$. To cover a large part of the global economy over a significantly long time period, we choose to use data of the four largest currency blocks, the US, the Euro Area, Japan and the UK over the sample period 1972Q4 to 2011Q4, involving a total of 157 quarterly observations. The data are taken from the OECD for GDP and its deflator and Reuters for the 3 month deposit, 10 year government benchmarks and nominal exchange rates, see the variable descriptions in Table 1 and information about data transformations in Table 2.

Table 1 Time series definitions and source

\begin{tabular}{|c|c|c|c|}
\hline \multicolumn{2}{|c|}{ Variable Description } & \multirow{2}{*}{$\begin{array}{l}\text { Source } \\
\text { OECD }\end{array}$} & \multirow{2}{*}{$\begin{array}{l}\text { EcoWin code } \\
\text { oecd }: \text { usa_naexcp01_stsaq }\end{array}$} \\
\hline$X_{t}^{U S}$ & US GDP by expenditure, Total, Current Prices, SA, USD & & \\
\hline$P_{t}^{U S}$ & US GDP implicit price deflator, SA, USD, 2005 chnd prices & OECD & $q n a:$ usa_463541155q \\
\hline$I_{t}^{U S}$ & US, Deposit Rates, 3 Month, USD & Reuters & ew : usa 14203 \\
\hline$R_{t}^{U S}$ & US Government Benchmarks, 10 Year, Yield, USD & Reuters & ew: usa14130 \\
\hline$X_{t}^{E A}$ & Euro Area (15), GDP, Current Prices, AR, SA, EUR & OECD & $o e: e a 15 \_g d p q$ \\
\hline$P_{t}^{E A}$ & Euro Area (15), GDP deflator, market prices, AR, (rebased) & OECD & $o e: e a 15 \_p g d p q$ \\
\hline$I_{t}^{E A}$ & $\begin{array}{l}\text { Euro Zone, Deposit Rates, } 3 \text { Month, EUR, (spliced with con- } \\
\text { structed series before 1986Q4) }\end{array}$ & Reuters & ew : ети 36103 \\
\hline$R_{t}^{E A}$ & Euro Zone, Government Benchmarks, 10 Year, Yield, EUR & Reuters & ew : eти 1413010 \\
\hline$X_{t}^{J P}$ & Japan, GDP, Current Prices, AR, JPY & OECD & $o e: j p n \_g d p q$ \\
\hline$P_{t}^{J P}$ & Japan, GDP deflator, market prices, AR, Index, 2005=100 & OECD & $o e: j p n \_p g d p q$ \\
\hline$I_{t}^{J P}$ & $\begin{array}{l}\text { Japan, Deposit Rates, } 3 \text { Month, JPY, } \\
\text { (before } 1979 \text { Treasury Bills) }\end{array}$ & Reuters & $\begin{array}{l}\text { ew }: \text { jpn } 36203 \\
\text { ew }: \text { jpn } 14010\end{array}$ \\
\hline$R_{t}^{J P}$ & Japan, Government Benchmarks, 10 Year, Yield, JPY & Reuters & ew: jpn 14020 \\
\hline$X_{t}^{U K K}$ & UK GDP by expenditure, Current prices, SA, GBP & OECD & $q n a: g b r \_695424946 q$ \\
\hline$P_{t}^{U K}$ & UK GDP implicit price deflator, SA, $2005=100$ & OECD & $q n a: g b r \_m 349072799 q$ \\
\hline$I_{t}^{U K}$ & UK, Deposit Rates, 3 Month, GBP & Reuters & $e w: g b r 3610310$ \\
\hline$R_{t}^{U K}$ & UK, Government Benchmarks, 10 Year, Yield, GBP & Reuters & ew : $g b r 14020$ \\
\hline$E_{t}^{E A}$ & Euro Zone, Spot Rates, USD/EUR, Average & Eurostat & ew : emu 19008 \\
\hline$E_{t}^{J P}$ & Japan, Spot Rates, USD/JPY, Close & Reuters & ew : jpn 19001 \\
\hline$E_{t}^{U K}$ & UK, Spot Rates, GBP/USD, Close & Reuters & ew : gbr 1900110 \\
\hline
\end{tabular}


Table 2 Model variables

\begin{tabular}{cl}
\hline \multicolumn{1}{c}{ Variable } & Description \\
\hline$\pi_{t}=\Delta \log P_{t}$ & rate of inflation \\
$\Delta y_{t}=\Delta \log Y_{t}$ & output growth \\
$i_{t}=\log \left(1+I_{t} / 400\right)$ & short-term interest rate \\
$r_{t}=\log \left(1+R_{t} / 400\right)$ & long-term interest rate \\
\hline
\end{tabular}

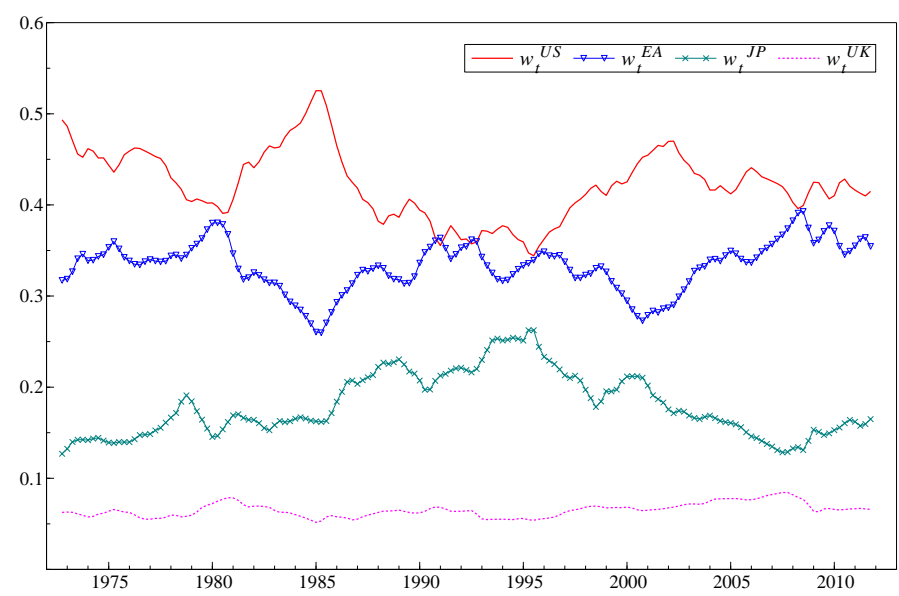

Figure 1 Countries' GDP weights

The aggregation of the country data to measures of the global economy are performed using the Divisia (1925) index, which ensures the optimal aggregation of quantities under changing prices in continuous time. In this paper, aggregation of all variables will be based on the countries' time-varying shares in 'global' GDP (G4 only). However, our results are robust to alternative aggregation methods such as fixed country weights.

Suppose we have GDP data for $K$ countries, where $X_{t}^{j}=P_{t}^{j} Q_{t}^{j}$ denotes the nominal GDP of country $j, Q_{t}^{j}$ the real GDP and $P_{t}^{j}$ the implicit price deflator. Then aggregation to global real GDP, $Q_{t}^{g}$, is performed by accumulating the countries' growth rates weighted by their time-varying GDP shares, $\bar{w}_{t}^{j}$ :

$$
\Delta \log Q_{t}^{g}=\sum_{j=1}^{K} \bar{w}_{t}^{j} \Delta \log Q_{t}^{j} \quad \text { for } t=1, \ldots, T .
$$

To construct $Q_{t}^{g}$, the $\log$ growth rates, $\Delta \log Q_{t}^{g}$, are cumulated and the exponential function is applied. The implicit price deflator is given by $X_{t}^{g} / Q_{t}^{g}$ where $X_{t}^{g}=\sum_{i=1}^{k} E_{t}^{i} X_{t}^{i}$. Finally the series is re-based on the last observation to equal the sum of the country levels, $Q_{T}^{g}=\sum_{j=1}^{K} Q_{T}^{j}$.

The country weights are given by the share of currency-adjusted total nominal GDP, where using nominal GDP and nominal exchange rates is equivalent to using real GDP and real ex- 
change rates:

$$
w_{t}^{j}=\frac{E_{t}^{j} X_{t}^{j}}{\sum_{i=1}^{K} E_{t}^{i} X_{t}^{i}} \quad \text { for } j=1, \ldots, K .
$$

As originally proposed by Törnqvist (1936), the weights are smoothed by taking moving averages of the weights of the contemporaneous and the previous period:

$$
\bar{w}_{t}^{j}=\frac{1}{2}\left(w_{t}^{j}+w_{t-1}^{j}\right) .
$$

The applied weights in the procedure can be seen in Figure 1. The full-sample average weights are for the US $42 \%$, for the Euro Area 33\%, for Japan $18 \%$ and for the UK 7\%. The resulting global time series, which are used in the rest of the paper, are plotted in Figure 2.
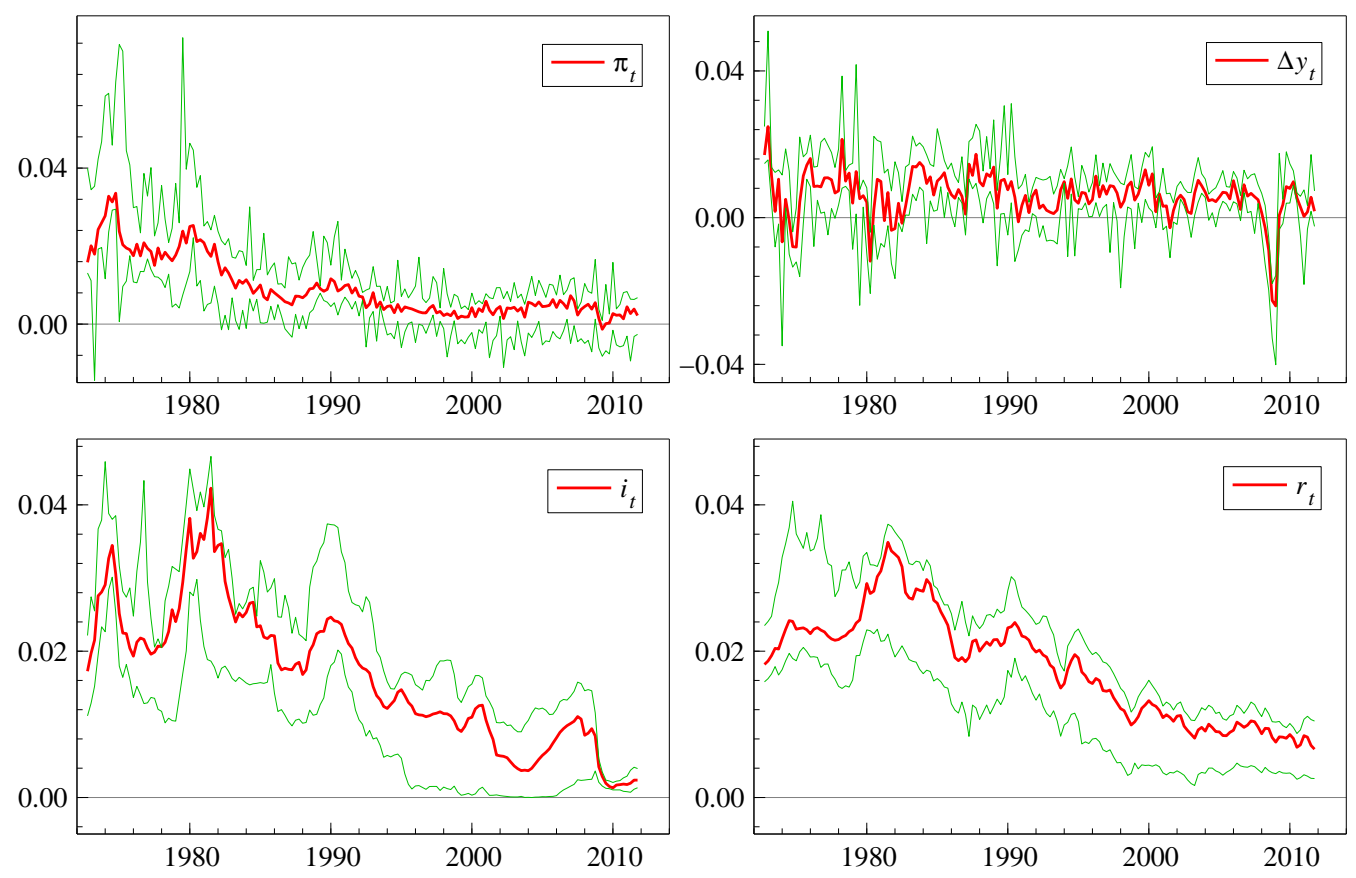

Figure 2 Inflation, $\pi_{t}$, output growth, $\Delta y_{t}$, short- and long-term interest rates, $i_{t}$ and $r_{t}$, of the global time series with the maxima and minima of the country series.

\section{The global cointegrated vector autoregression}

\subsection{The statistical model}

We commence from a four-dimensional Vector Autoregressive (VAR) model of order $p$, without any equation-specific restrictions, to capture the characteristics of the data:

$$
\boldsymbol{y}_{t}=\boldsymbol{\mu}_{0}+\boldsymbol{\mu}_{1} t+\sum_{j=1}^{p} \boldsymbol{A}_{j} \boldsymbol{y}_{t-j}+\varepsilon_{t}
$$


where $\varepsilon_{t} \sim \operatorname{NID}(\mathbf{0}, \boldsymbol{\Sigma})$ is a Gaussian white noise process.

Mapped to its Vector Equilibrium Correction Mechanism (VECM) representation:

$$
\Delta \boldsymbol{y}_{t}=\boldsymbol{\mu}_{0}+\boldsymbol{\mu}_{1} t+\boldsymbol{\Pi} \boldsymbol{y}_{t-1}+\sum_{j=1}^{p-1} \boldsymbol{\Gamma}_{j} \Delta \boldsymbol{y}_{t-j}+\varepsilon_{t},
$$

the Johansen trace testing procedure for determining the cointegration $\operatorname{rank}, r=\operatorname{rank}(\boldsymbol{\Pi})$, is then applied. For a cointegrated vector process, the reduced-rank matrix $\Pi$ can be decomposed into the $4 \times r$ dimensional loading matrix, $\boldsymbol{\alpha}$, and $4 \times r$ cointegration matrix, $\boldsymbol{\beta}$, containing the information of the long-run structure of the model, i.e. $\Pi=\boldsymbol{\alpha} \boldsymbol{\beta}^{\prime}$. The trend is restricted to the cointegration space, so that $\mu_{1}=\boldsymbol{\alpha} \boldsymbol{\delta}$, where $\delta$ is $r$ dimensional. The Johansen procedure delivers unique estimates of $\boldsymbol{\alpha}$ and $\boldsymbol{\beta}$ as a result of requiring $\boldsymbol{\beta}$ to be orthogonal and normalized. These estimates provide a value for the unrestricted log-likelihood function to be compared to the log-likelihood under economically meaningful overidentifying restrictions, $\boldsymbol{\beta}^{r}$ :

$$
\Delta \boldsymbol{y}_{t}=\boldsymbol{\mu}_{0}+\boldsymbol{\alpha}\left(\boldsymbol{\beta}^{r \prime} \boldsymbol{y}_{t-1}+\boldsymbol{\delta} t\right)+\sum_{j=1}^{p-1} \boldsymbol{\Gamma}_{j} \Delta \boldsymbol{y}_{t-j}+\varepsilon_{t}
$$

Following Engle and Granger (1987) a VAR model with I(1) variables and cointegration between the variables can be expressed in a moving average representation. The Granger representation is a trend-cycle decomposition of the system in (6):

$$
\boldsymbol{y}_{t}=\tilde{\boldsymbol{\beta}}_{\perp}^{r} \boldsymbol{\alpha}_{\perp}^{\prime} \sum_{i=1}^{t} \varepsilon_{i}+\tau_{1} t+\tau_{0}+\boldsymbol{\rho}_{t}
$$

where $\tilde{\boldsymbol{\beta}}_{\perp}^{r}=\boldsymbol{\beta}_{\perp}^{r}\left(\boldsymbol{\alpha}_{\perp}^{\prime} \boldsymbol{\Gamma} \boldsymbol{\beta}_{\perp}^{r}\right)^{-1}$ and $\boldsymbol{\Gamma}=\mathrm{I}-\boldsymbol{\Gamma}_{1}-\ldots-\boldsymbol{\Gamma}_{k-1} \cdot{ }^{1}$ The first term in equation (7) is the contribution of the stochastic trend in the decomposition. We can define $\xi_{t}=\alpha_{\perp}^{\prime} \sum_{i=1}^{t} \varepsilon_{i}$, with $\varepsilon_{i}$ being the residuals of the restricted VECM in (6), as the stochastic trend of the system, so that $\tilde{\boldsymbol{\beta}}_{\perp}^{r}$ can be interpreted as a loading matrix linking the stochastic trend to each individual variable, see Johansen (1995). The second term in equation (7) is a deterministic trend, the third term the influence of the initial values and the final term $\rho_{t}$ is a stationary component, which can be interpreted as the cycle of the process.

\subsection{The cointegration relations}

The dynamics of our global rates of inflation, economic growth, and short- and long-term interest rates, $\boldsymbol{y}_{t}=\left(\pi_{t}, \Delta y_{t}, i_{t}, r_{t}\right)^{\prime}$, can be captured by a VAR(5) with an unrestricted constant and a linear trend restricted to the cointegration space. ${ }^{2}$ Table 3 shows the results for the Johansen (1995) test for $I(1)$ cointegration, which indicate a cointegration rank of three. Thus

\footnotetext{
${ }^{1}$ The orthogonal complement matrix of $\boldsymbol{\alpha}$, denoted $\boldsymbol{\alpha}_{\perp}$, is defined such that $\boldsymbol{\alpha}^{\prime} \boldsymbol{\alpha}_{\perp}=\mathbf{0}$ and $\operatorname{rank}\left(\boldsymbol{\alpha}, \boldsymbol{\alpha}_{\perp}\right)=4$.

${ }^{2}$ A shorter lag order would not change the result of the following Johansen rank test but would lead to autocorrelation in the residuals.
} 
there is only one unit root in the system.

Table 3 Johansen likelihood ratio trace test of $H_{0}:$ rank $\leq r$. $\operatorname{VAR}(5)$ with constant and trend

\begin{tabular}{cccc}
\hline & eigenvalue & trace test & prob \\
\hline$r=0$ & 0.270 & $110.65^{* *}$ & {$[0.000]$} \\
$r \leq 1$ & 0.193 & $61.24^{* *}$ & {$[0.000]$} \\
$r \leq 2$ & 0.122 & $27.56^{*}$ & {$[0.028]$} \\
$r \leq 3$ & 0.045 & 7.17 & {$[0.337]$} \\
\hline **
\end{tabular}

The empirical modeling procedure for finding the cointegration relations follows Juselius (2006). We start by considering standard economic relations as candidates for three cointegration relations. The real interest rate (predicted by the Fisher hypothesis) and the term spread (predicted by the expectations hypothesis of the term structure) are plotted in Figure 3 . The growth rate of GDP, which could constitute a degenerated cointegration vector, was displayed in Figure 2.
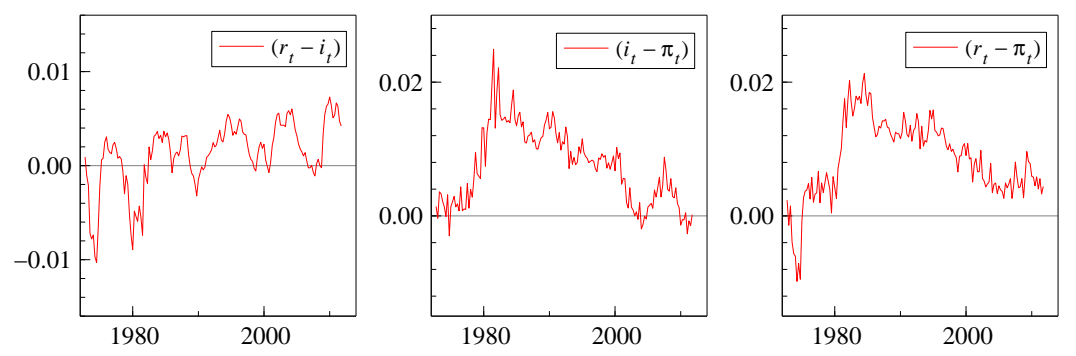

Figure 3 Global term spread and real short-and long-term interest rates.

The level shift in 1981, coinciding with the Volcker disinflation, seems too large to accept the real rates as cointegrating vectors. On the other hand a shift dummy at this point in time seems not to be appropriate to solve this non-stationarity, because the upward shift occurs during a period of three years and the downward shift is a very slow decline taking place up to the end of the sample. The term spread together with a trend appears to a strong candidate for a cointegrating vector.

The cointegration relationships are found by checking statistical acceptability and agreeability with economic theory. The following cointegrating vectors were identified:

(i) Output growth.

$$
\Delta y_{t}+0.00003 t \sim I(0) .
$$

The first cointegrating vector is trend stationary global output growth rate. The negative trend of the global output growth is partly due to large negative growth rates during the 


\section{Great Recession.}

(ii) Term spread.

$$
r_{t}-i_{t}-0.00003 t \sim I(0) .
$$

The second cointegrating vector is the stationary global spread between long and shortterm interest rates. The positive trend of the term spread reflects to large extend the accommodating monetary policy since the Global Financial Crisis.

The over-identifying restrictions for these two vectors, leaving the third vector unrestricted, are accepted by the likelihood ratio (LR) test with $\chi^{2}(2)=2.45$ and a p-value of 0.29 . Conditional on the conventional cointegration relations (i) and (ii) and thus excluding $\Delta y_{t}$ and $i_{t}$ (or $r_{t}$ ), the just-identified third cointegration vector is given by:

$$
r_{t}+\underset{(0.25)}{1.17} \pi_{t}+\underset{(0.000038)}{0.00029} t \sim I(0)
$$

This cointegration vector is inconsistent with the notion of a stationary real interest rate, $r_{t}-\pi_{t}-\gamma_{r-\pi} t$, which implies a wrong sign on the $\pi_{t}$ coefficient and is clearly rejected with a p-value of 0.00 . We can however simplify the third long-run relationship as follows:

(iii) Inflation climate.

$$
\frac{1}{2}\left(\pi_{t}+r_{t}\right)+0.00013 t \sim I(0)
$$

The final cointegration vector is given by the global inflation climate, measuring longterm inflation expectations as an average of current inflation and - in spirit of the Fisher hypothesis - market expectations of future inflation embedded in the nominal bond yield. ${ }^{3}$ The secular downward trend in the inflation climate from 'Great Inflation' to 'Great Moderation' and then to 'Great Recession' is captured by the deterministic trend.

The over-identifying restrictions imposed on the cointegration space by (i) - (iii) are accepted with a likelihood ratio test statistic of $\chi^{2}(3)=2.64$ and a p-value of 0.45 . The three cointegrating relations are plotted in Figure 4 . Table 4 displays the full estimation results for the long-run dynamics of the system. The cointegrating relations are the pulling forces ensuring the partial reversal of the economy to the steady state. The deterministic trends are moving these steady states.

\footnotetext{
${ }^{3}$ For US data it can be shown that our inflation climate measure is a good proxy for survey data of long-term inflation expectations. Due to the lack of data availability, survey data could not be utilized for the the global model.
} 


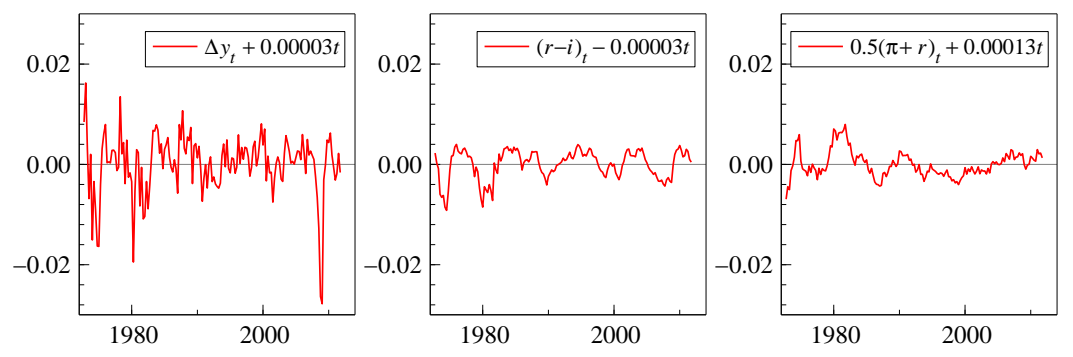

Figure 4 The three cointegrating vectors.

Table 4 Cointegration vectors and loadings, t-values in brackets

\begin{tabular}{|c|c|c|c|c|c|c|}
\hline & \multicolumn{3}{|c|}{ Cointegration vectors } & \multicolumn{3}{|c|}{ Loadings } \\
\hline & $\beta_{1}$ & $\beta_{2}$ & $\beta_{3}$ & $\alpha_{1}$ & $\alpha_{2}$ & $\alpha_{3}$ \\
\hline$\pi_{t}$ & 0 & 0 & 0.5 & $\begin{array}{r}0.032 \\
(0.61)\end{array}$ & $\begin{array}{r}-0.038 \\
(-0.45)\end{array}$ & $\begin{array}{c}-0.285^{* *} \\
(-3.89)\end{array}$ \\
\hline$\Delta y_{t}$ & 1 & 0 & 0 & $\begin{array}{c}-0.667^{* *} \\
(-4.77)\end{array}$ & $\begin{array}{l}0.607^{* *} \\
(2.70)\end{array}$ & $\begin{array}{c}-0.498^{*} \\
(-2.52)\end{array}$ \\
\hline$i_{t}$ & 0 & -1 & 0 & $\begin{array}{l}0.112^{*} \\
(2.43)\end{array}$ & $\begin{array}{r}0.021 \\
(0.28)\end{array}$ & $\begin{array}{r}-0.095 \\
(-1.45)\end{array}$ \\
\hline$r_{t}$ & 0 & 1 & 0.5 & $\begin{array}{r}0.002 \\
(0.10)\end{array}$ & $\begin{array}{c}-0.112^{* *} \\
(-2.73)\end{array}$ & $\begin{array}{c}-0.076^{*} \\
(-2.10)\end{array}$ \\
\hline trend & $\begin{array}{c}0.000034^{* *} \\
(3.14)\end{array}$ & $\begin{array}{c}-0.000033^{* *} \\
(-4.00)\end{array}$ & $\begin{array}{c}0.000134^{* *} \\
(14.2)\end{array}$ & & & \\
\hline
\end{tabular}

\subsection{The common stochastic trend}

After identifying the long-run equilibrium of our model, we are going to compute the cumulated residuals, see Figure 5 and derive the global common stochastic trend. ${ }^{4}$

With the parameter matrices $\boldsymbol{\alpha}, \boldsymbol{\beta}$ and $\boldsymbol{\Gamma}_{i}$ given, $\tilde{\boldsymbol{\beta}}_{\perp}^{r}$ and $\boldsymbol{\alpha}_{\perp}$ are as follows:

$$
\tilde{\boldsymbol{\beta}}_{\perp}^{r}=\left(\begin{array}{r}
-1 \\
0 \\
1 \\
1
\end{array}\right) \quad \text { and } \quad \boldsymbol{\alpha}_{\perp}=\left(\begin{array}{r}
-0.226 \\
0.034 \\
0.257 \\
0.308
\end{array}\right) \text {. }
$$

The normalised loading matrix $\tilde{\boldsymbol{\beta}}_{\perp}^{r}$, which links the stochastic trend to each individual variable, shows that an increase in the stochastic trend leads to a decrease in inflation and an increase in the interest rates. The global common stochastic trend calculated with $\alpha_{\perp}$ and the system residuals can be seen in Figure 6. As a robustness check, three model alternatives are

\footnotetext{
${ }^{4}$ It is important noticing that, in contrast to cointegration relations, the common stochastic trend is not invariant to the inclusion of additional variables. Focussing here on central macroeconomic variables, we claim to give a good description of a driving trend of the world economy.
} 

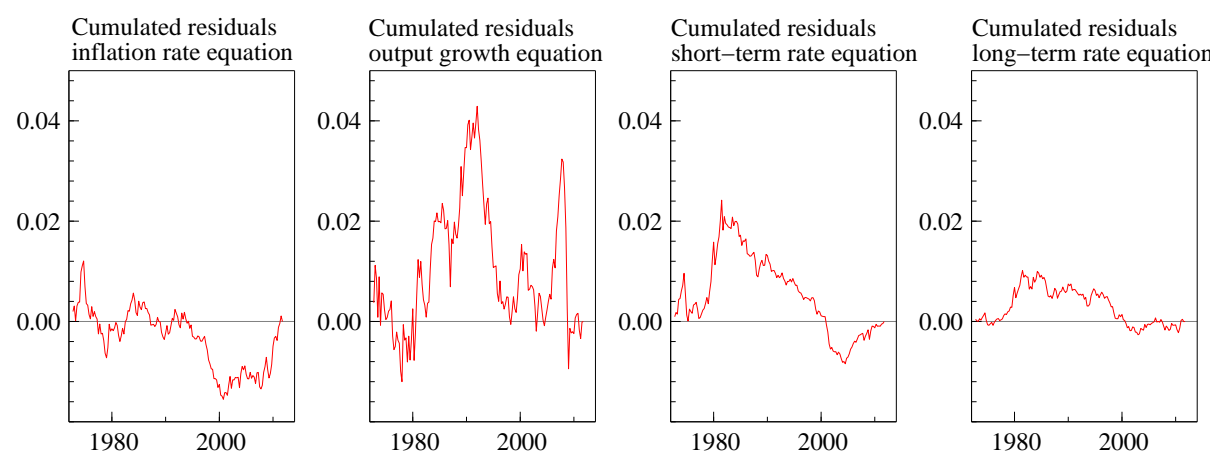

Figure 5 Cumulated residuals of the system equations

displayed: The unrestricted CVAR, the CVAR with the identified cointegration vectors, $\boldsymbol{\beta}^{r}$, and finally we additionally allow for the loading matrix to be restricted $\boldsymbol{\alpha}^{r}$, where the insignificant parameters of the $\alpha$ matrix are constrained to zero. ${ }^{5}$ The common stochastic trends of all three model options are very similar. In other words, the results are robust with regard to the restrictions imposed on the cointegration relationships.
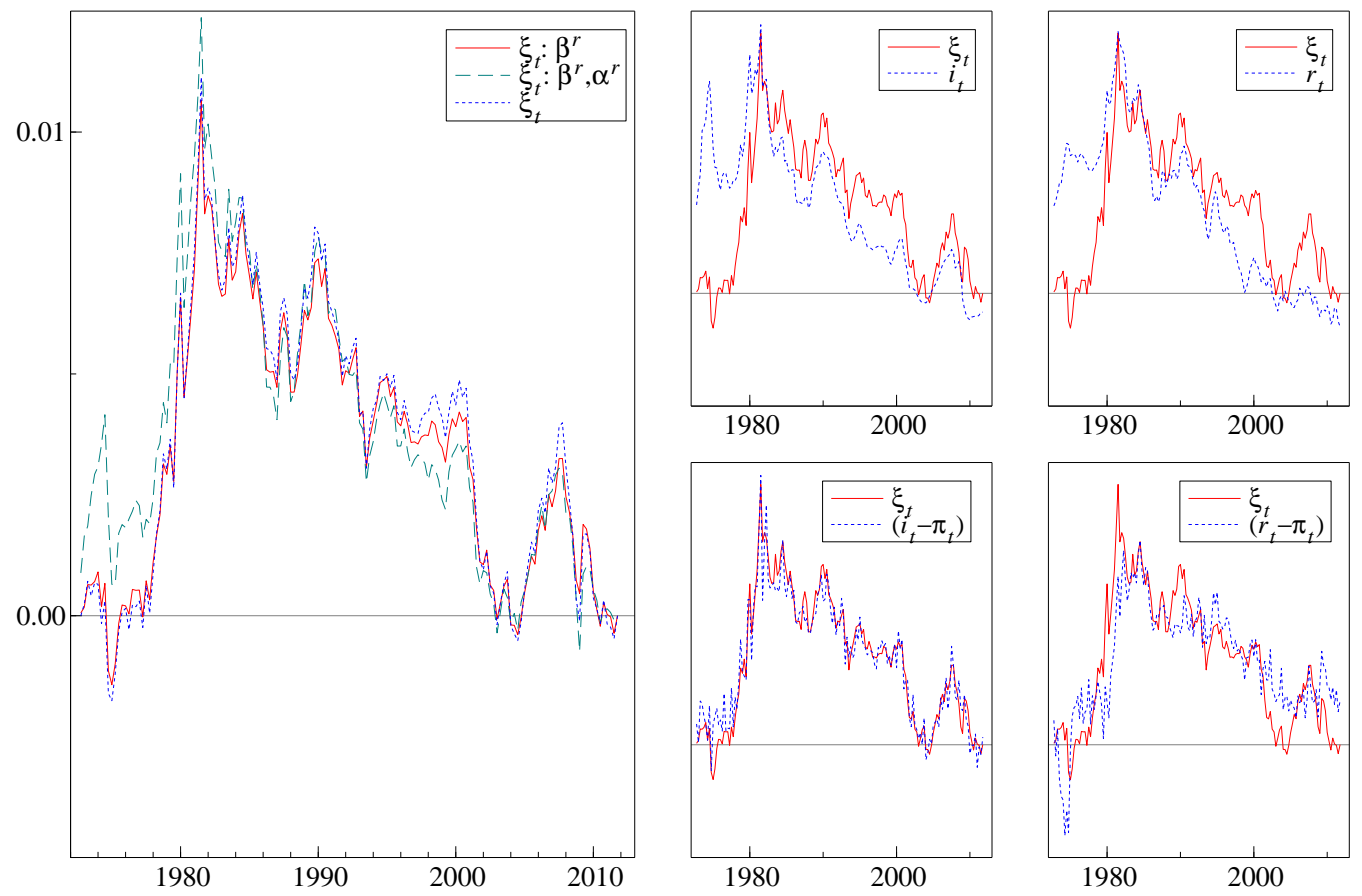

Figure 6 The global common stochastic trend, $\xi_{t}$, in the baseline model with $\boldsymbol{\beta}^{r}$, the model with restricted $\boldsymbol{\beta}^{r}$ and $\boldsymbol{\alpha}^{r}$, and the unrestricted CVAR (left panel), compared to nominal and real short/long-term interest rates scaled for equal means and ranges (right panels).

A comparison of the common trend of the baseline model with nominal and real interest rates shows that the real short-term rate mimics the stochastic trend closely, with a correlation

\footnotetext{
${ }^{5}$ The restrictions passed the likelihood ratio test, after which the model is re-estimated.
} 
of $97 \%$, see Figure 6. Having found this high correlation we test in the following whether the common stochastic trend is determined by shocks to the real short-term interest rate, hence only shocks to the real short-term interest rate are present in the stochastic trend, so $\boldsymbol{\alpha}_{\perp}$ has the following form:

$$
H_{o}^{1}: \boldsymbol{\alpha}_{\perp}^{\prime}=(-1,0,1,0)
$$

Recalling how the orthogonal complement is defined, the test of $H_{o}^{1}$ is implemented as a test of the following linear restrictions on $\alpha$ :

$$
\boldsymbol{R} \boldsymbol{\alpha}=\boldsymbol{r} \text { with } \boldsymbol{R}=\boldsymbol{\alpha}_{\perp}^{\prime} \text { and } \boldsymbol{r}=\mathbf{0} .
$$

Where in the case of $H_{o}^{1}$, the test hypotheses are of the form

$$
-\alpha_{1, i}+\alpha_{3, i}=0 \text { for all } i=1, \ldots, r
$$

Under preservation of the cointegration rank and the full rank of $\left(\boldsymbol{\alpha}, \boldsymbol{\alpha}_{\perp}\right)$, the LR test statistic is $\chi^{2}(r)$. For the baseline model, with a test result of $\chi^{2}(3)=5.456$ and a p-value of 0.141 , the hypothesis can not be rejected. Finally we check on this restricted model that the rank condition for $\boldsymbol{\alpha}_{\perp}, \operatorname{rank}\left(\boldsymbol{\alpha}, \boldsymbol{\alpha}_{\perp}\right)=K$ is not violated:

$$
H_{o}^{2}:\left(\alpha_{21}, \ldots, \alpha_{2 r}\right)=0 \text { and } H_{o}^{3}:\left(\alpha_{41}, \ldots, \alpha_{4 r}\right)=0 .
$$

Both hypothesis can clearly be rejected, $H_{o}^{2}$ with a test result of $\chi^{2}(3)=33.12$ and a p-value of 0.000 and $H_{o}^{3}$ with a test result of $\chi^{2}(3)=18.72$ and a p-value of also 0.000 .

To sum up, the global common trend is largely determined by shocks to the real short-term interest rate. Because monetary policy is strongly influencing the real short-term interest rate, it seems to be an 'unsystematic' driver of the global economic system.

\section{Identifying the economic forces driving the global common stochastic trend}

The Volcker disinflation era, during which monetary policy had a strongly exogenous character, had extraordinarily dominant influence on the macro history in the last 40 years. To demonstrate this we remove the effect of the Volcker disinflation period from the common stochastic trend, with the consequence that the stochastic trend looses its property of a stochastic trend and is getting stationary, according to a unit root test.

The creation of a centred Volcker step dummy, $\zeta_{t}$, from 1979Q4 until 1982Q3 follows historical events according to Goodfriend and King (2005). Additionally, we accumulate the dummy, $\sum_{i=1}^{t} \zeta_{i}$, in order to reflect the presence of a unit root in the system and to capture the long-term effects of the Volcker disinflation.

We add the unrestricted dummy, $\zeta_{t}$, in the VAR representation of the model, what leads to 
a term $\tilde{\boldsymbol{\beta}}_{\perp}^{r} \boldsymbol{\alpha}_{\perp}^{\prime} \sum_{i=1}^{t} \zeta_{i}$ in the Granger moving average representation. The dummies can be seen in Figure 7.
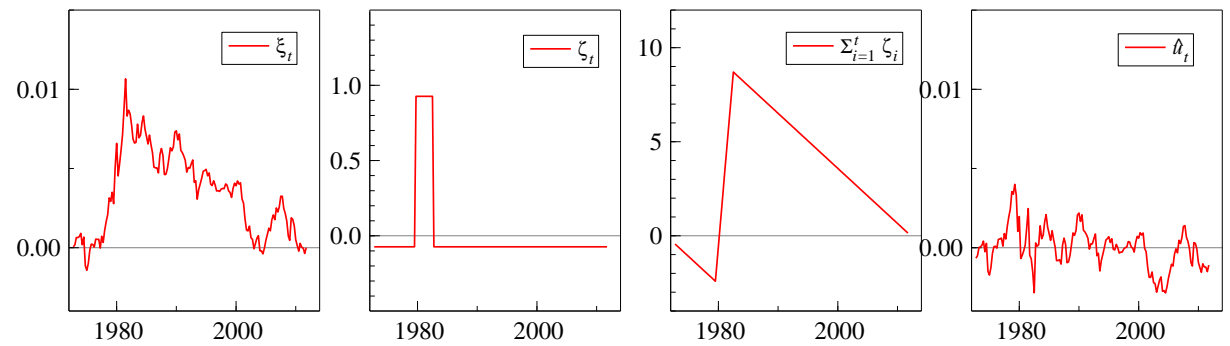

Figure 7 The common stochastic trend, $\xi_{t}$, the centred step dummy, $\zeta_{t}$, its cumulation, $\Sigma_{i=1}^{t} \zeta_{i}$, and the residuals, $\widehat{u}_{t}$.

To remove the effect of the Volcker disinflation from the common stochastic trend we regress the common stochastic trend on a constant and the two dummies, using HAC standard errors. The t-values are shown in brackets:

$$
\xi_{t}=\underset{(3.62)}{0.0013}+\underset{(8.26)}{0.0040} \zeta_{t}+\underset{(9.25)}{0.0006} \Sigma_{i=1}^{t} \zeta_{i}+\widehat{u}_{t}
$$

The residuals, $\widehat{u}_{t}$, of this model are plotted in the last panel of Figure 7 . When investigating the residuals using an Augmented Dickey-Fuller test with short-run dynamics up to lag six and a constant, the hypothesis of a unit root can clearly be rejected with a t-value of 3.27 at a 5\% critical value of 2.88 , when ignoring a possible detrending effect on the limiting distribution. This result suggests that it is indeed the Volcker disinflation policy that produced the global common stochastic trend in rates of interest and inflation. Note that the major features remaining and now dominating $\widehat{u}_{t}$ are the periods of accommodating monetary policy after September 11, 2001, and the global financial crisis in 2008.

As an alternative test we redo the cointegration analysis performed in $\$ 3$ by including the two Volcker dummies into the VAR(5). The centred step dummy enters unrestrictedly as well as the constant, while the cumulated dummy and the trend is restricted to the cointegration space:

$$
\boldsymbol{y}_{t}=\tilde{\boldsymbol{\mu}}_{0}+\tilde{\boldsymbol{\mu}}_{1} t+\boldsymbol{\nu}_{0} \zeta_{t}+\boldsymbol{\nu}_{1} \Sigma_{i=1}^{t} \zeta_{i}+\sum_{j=1}^{p} \tilde{\boldsymbol{A}}_{j} \boldsymbol{y}_{t-j}+\tilde{\varepsilon}_{t}
$$

where $\tilde{\varepsilon}_{t} \sim \operatorname{NID}(\mathbf{0}, \tilde{\Sigma})$. By taking the Volker disinflation period explicitly into account in the full system, it can be shown with a Johansen trace test, see Table 5, that the system has now full rank. The unit root is removed. 
Table 5 Johansen cointegration rank trace test for modified system:

$\operatorname{VAR}(5)$ with centred step dummy, $\zeta_{t}$, cumulated dummy, $\Sigma_{i=1}^{t} \zeta_{i}$, restricted trend and unrestricted constant.

\begin{tabular}{|c|c|c|c|}
\hline & eigenvalue & trace test & p-val \\
\hline$r=0$ & 0.317 & $129.22^{* *}$ & [0.000] \\
\hline$r \leq 1$ & 0.180 & $69.30^{\text {** }}$ & {$[0.000]$} \\
\hline$r \leq 2$ & 0.151 & $38.20^{\text {** }}$ & {$[0.001]$} \\
\hline$r \leq 3$ & 0.077 & $12.56^{*}$ & [0.048] \\
\hline
\end{tabular}

\section{Robustness Analysis}

In the previous section we have shown that the common stochastic trend of our small global macro system was driven by the Volcker disinflation policy. However, it remains to be shown whether this finding is a statistical artifact caused by the weight of the US economy in the Divisia index or if it describes a truly global phenomenon that affected the macroeconomies of all four currency blocks. ${ }^{6}$ To answer this question we will in the following replicate our analysis on the country level. We will start with the cointegration properties of the four macroeconomies, then consider the country-specific common stochastic trends and close with measuring the contribution of the Volcker disinflation period.

Table 6 Global and country-level VARs:

Johansen trace test and identification of cointegration vectors

\begin{tabular}{|c|c|c|c|c|c|}
\hline & G4 & US & EA & JP & UK \\
\hline \multicolumn{6}{|c|}{ Lag order (AIC determined) } \\
\hline$p$ & 5 & 5 & 2 & 3 & 4 \\
\hline \multicolumn{6}{|c|}{ Johansen tracetest ( $\mathrm{p}$-values) } \\
\hline$r=0$ & $0.000^{* *}$ & $0.000^{* *}$ & $0.000^{* *}$ & $0.000^{* *}$ & $0.000^{* *}$ \\
\hline$r \leq 1$ & $0.000^{* *}$ & $0.007^{* *}$ & $0.000^{* *}$ & $0.000^{* *}$ & $0.001^{* *}$ \\
\hline$r \leq 2$ & $0.028^{*}$ & 0.053 & $0.023^{*}$ & $0.002^{* *}$ & $0.003^{* *}$ \\
\hline$r \leq 3$ & 0.337 & 0.290 & 0.282 & 0.111 & $0.021^{*}$ \\
\hline \multicolumn{6}{|c|}{ LR test (p-val) of overidentifying restrictions $(8)-(11)$} \\
\hline$\chi^{2}(3)$ & 0.451 & 0.237 & 0.081 & 0.629 & $0.024^{*}$ \\
\hline
\end{tabular}

Table 6 shows the cointegration results for the US, Euro Area, Japan and the UK in comparison to our global system denoted G4. The cointegration rank of three is generally accepted for all four countries but with some variation in significance: straightforwardly at $5 \%$ in the case of EA and JP, with a p-value of 0.053 a rank of two could be marginally accepted at $5 \%$ for the US, and requiring a $1 \%$ significance level for the UK with a full rank resulting at $5 \%$. The

\footnotetext{
${ }^{6} \mathrm{We}$ are grateful to an unknown referee for suggesting this line of inquiry.
} 


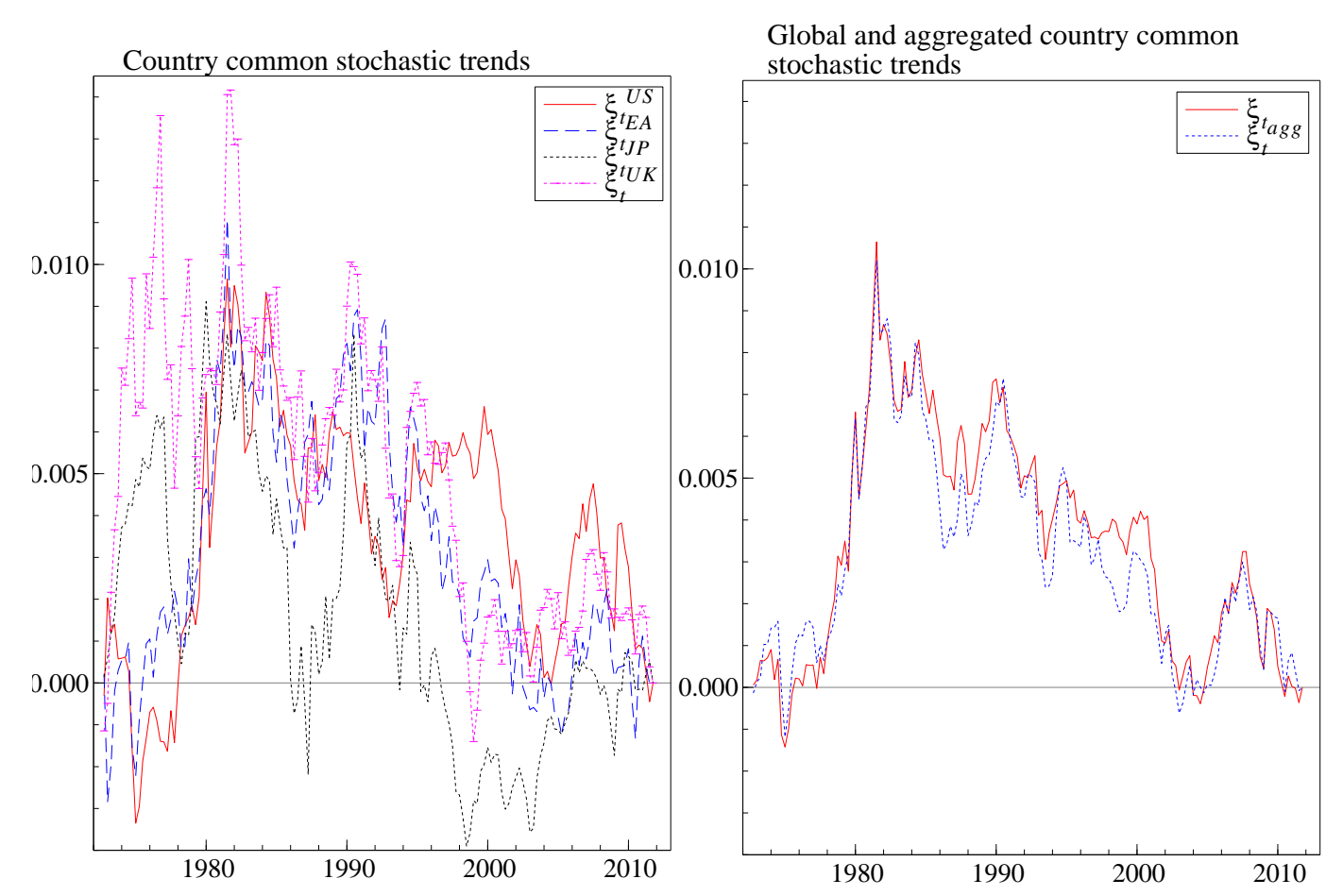

Figure 8 The common stochastic trends of the four country CVARs (left) and their aggregate in comparison to the global common stochastic trend (right).

Likelihood Ratio test supports the restrictions on the cointegration space imposed on the global CVAR also for the four country CVARs of rank three, with the UK being again the weakest link with a p-value of $0.024 .^{7}$

The resulting common stochastic trends of the four country CVARs are plotted in the left panel of Figure 8. The right panel compares their aggregate, $\xi_{t}^{a g g}=\sum_{i=1}^{4} \bar{w}_{t}^{i} \xi_{t}^{i}$ with $\bar{w}_{t}^{i}$ being the time-varying GDP weight of the Divisia index, to the global common stochastic trend, $\xi_{t}$, derived in $\S 3.3$. Clearly both time series are strikingly similar, confirming that both the cointegration vectors as well as the global common stochastic trends are common features of the four currency blocks. Next we will investigate the contribution of the Volcker disinflation policy experiment to the common stochastic trends of the country CVARs.

In order to analyse how the Volcker policies affected the individual countries, we run a further experiment by regressing the country-specific stochastic trends on our Volcker dummies. If the Volcker disinflation was the major driving force on the country level as we have found for the global system, the dummies should be highly significant and produce stationary residuals. The results of the Volcker regression for the four country common stochastic trends and their aggregate are summarized in Table 7, and the residuals are plotted in Figure 9 in comparison to the country common stochastic trend. As shown before for the global model, the Volcker

\footnotetext{
${ }^{7}$ Given the relatively small weight of the UK, the exclusion of the UK trend would not significantly change the properties of the aggregated common stochastic trend.
} 
dummies are highly relevant for the stochastic trends of all 5 considered cases. Particularly for the US and the Euro Area, the dummies explain 66 to 69 percent in the variation of the stochastic trend with both dummies being highly statistically significant.

Table 7 Global and country-level VARs:

Common stochastic trends and the Volcker disinflation policies

\begin{tabular}{|c|c|c|c|c|c|c|}
\hline & G4 & G4 agg & US & EA & $\mathrm{JP}$ & UK \\
\hline \multicolumn{7}{|c|}{ Volcker Regression (t value) $)^{\dagger}$} \\
\hline$\zeta_{t}$ & $8.26^{* *}$ & $12.20^{* *}$ & $9.26^{* *}$ & $7.03^{* *}$ & $11.10^{* *}$ & $4.62^{* *}$ \\
\hline$\sum_{i=1}^{t} \zeta_{i}$ & $9.25^{* *}$ & $7.82^{* *}$ & $9.29^{* *}$ & $7.93^{* *}$ & 0.34 & 1.37 \\
\hline$R^{2}$ & 0.76 & 0.72 & 0.69 & 0.66 & 0.27 & 0.21 \\
\hline \multicolumn{7}{|c|}{ ADF test statistic (t value) $)^{\ddagger}$} \\
\hline$\xi_{t}$ & -1.568 & -1.841 & -2.126 & -1.820 & -1.930 & -2.378 \\
\hline$\hat{u}_{t}$ & $\begin{array}{c}-3.267^{*} \\
{[0.018]}\end{array}$ & $\begin{array}{c}-2.937^{*} \\
{[0.044]}\end{array}$ & $\begin{array}{c}-3.846^{* *} \\
{[0.003]}\end{array}$ & $\begin{array}{r}-2.532 \\
{[0.110]}\end{array}$ & $\begin{array}{r}-2.636 \\
{[0.088]}\end{array}$ & $\begin{array}{r}-2.716 \\
{[0.074]}\end{array}$ \\
\hline
\end{tabular}

As can be seen in Figure 9, the main features of these country stochastic trends are removed and the residuals are closer to be stationary. The Volcker policies seem to have been a major factor in all countries, but have been especially relevant for the US and the Euro Area. Indeed, the ADF test results reported in Table 7 indicate stationarity for the residuals of the US and aggregated stochastic trends. For the other three countries the evidence is weaker but still noticable with p-values of 0.074 (UK), 0.088 (JP) and 0.11 (EA). While the Volcker disinflation is a major factor in those countries, there are also country-specific macroeconomic events at work that contribute to the nonstationarity of the system. Overall, the results are reassuring for our modelling procedure.

\section{Conclusion}

The aim of this paper was to shed light on the pulling forces - the cointegration relations - and pushing forces - the common stochastic trend - of the global economy. Three stable long-run relationships emerged: output growth, the term spread and our inflation climate measure. The common driving trend of the global economy turned out to be closely related to the real shortterm interest rate, which in turn could be traced back to the stance of monetary policy. The Volcker disinflation emerged as the major macroeconomic event of the post-Bretton-Woods period, forming the global macro-finance common stochastic trend. A presence of the Volcker effect could also be established for all individual countries. 

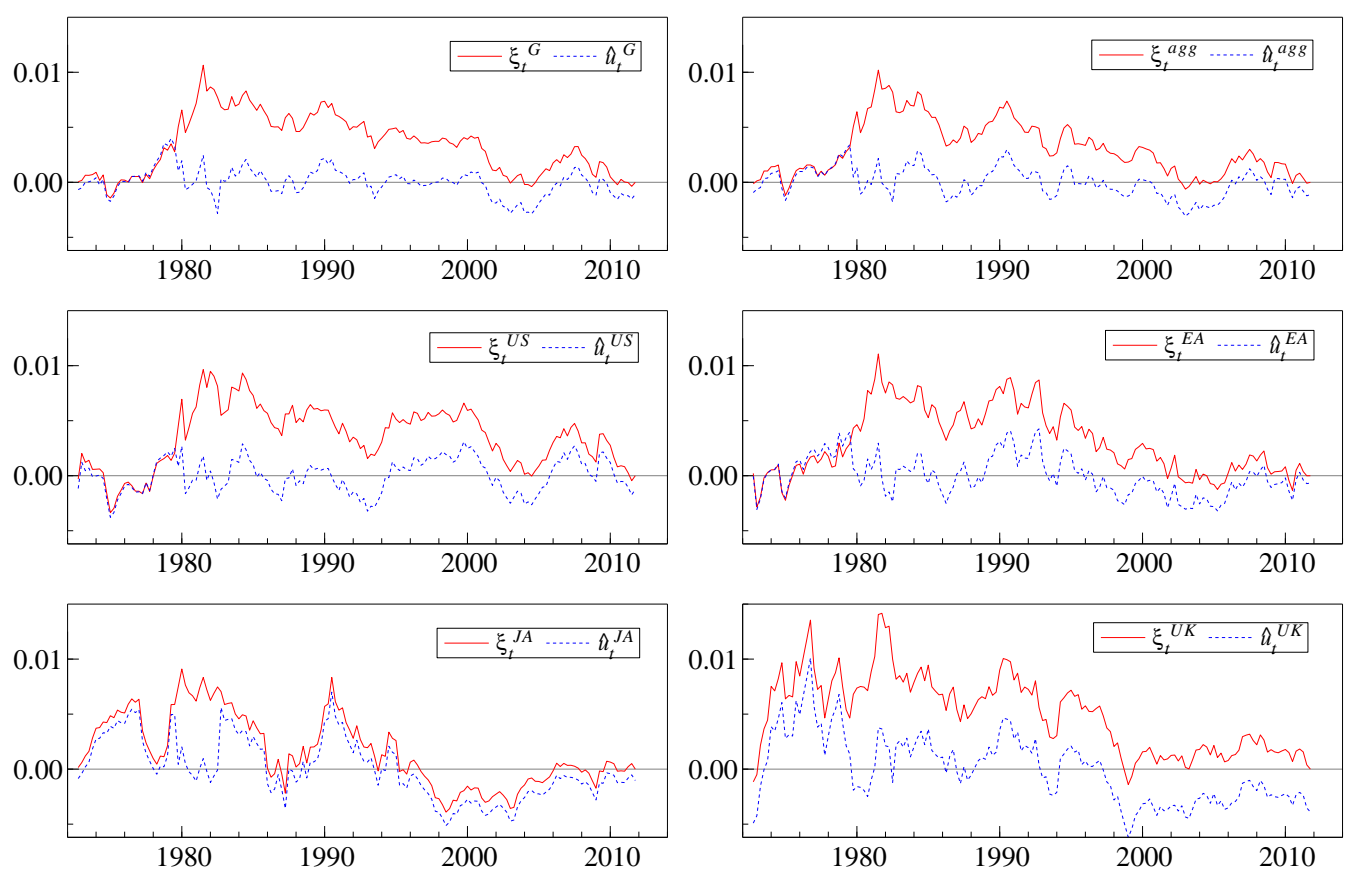

Figure 9 Common stochastic trends on global, aggregated and country level versus the residuals of the corresponding Volcker regression

\section{References}

Bai, J. and P. Perron (1998). Estimating and testing linear models with multiple structural changes. Econometrica, 47-78. 2

Blanchard, O. J., L. H. Summers, A. S. Blinder, and W. D. Nordhaus (1984). Perspectives on high world real interest rates. Brookings Papers on Economic Activity 2, 273-334. 2

Divisia, F. (1925). L'Indice Monétaire et la Théorie de la Monnaie. Revue d'Economie Politique 39, 980-1008. 4

Engle, R. F. and C. W. Granger (1987). Co-integration and error correction: Representation, estimation, and testing. Econometrica 55, 251-276. 6

Forni, M., M. Hallin, M. Lippi, and L. Reichlin (2000). The generalized dynamic-factor model: Identification and estimation. The Review of Economics and Statistics 82, 540-554. 2

Garcia, R. and P. Perron (1996). An analysis of the real interest rate under regime shifts. The Review of Economics and Statistics 78, 111-125. 2

Goodfriend, M. and R. G. King (2005). The Incredible Volcker Disinflation. Journal of Monetary Economics 52, 981-1015. 2, 11 
Johansen, S. (1995). Likelihood-Based Inference in Cointegrated Vector Autoregressive Models. Oxford University Press. 2, 6

Juselius, K. (2006). The cointegrated VAR model. Oxford: Oxford University Press. 2, 7

Kaldor, N. (1957). A model of economic growth. The Economic Journal, 591-624. 2

Rapach, D. E. and C. E. Weber (2004). Are real interest rates really nonstationary? New evidence from tests with good size and power. Journal of Macroeconomics 26, 409-430. 2

Rapach, D. E. and M. E. Wohar (2005). Regime changes in international real interest rates: Are they a monetary phenomenon? Journal of Money, Credit and Banking 37, 887-906. 2

Rose, A. K. (1988). Is the real interest rate stable? The Journal of Finance 43, 1095-1112. 2

Törnqvist, L. (1936). The Bank of Finland's Consumption Price Index. Bank of Finland Monthly Bulletin 10, 1-8. 5 